\title{
Possibility of Applying the Concept of Coaching in Serbia
}

\author{
Živka Pržulj ${ }^{1}$, Svetolik Kostadinović ${ }^{2}$,Snežana Videnović ${ }^{3}$ \\ ${ }^{1}$ Faculty of Banking, Insurance et Finance, University UNION, Belgrade, Serbia \\ ${ }^{2}$ Alfa University, Belgrade, Serbia \\ ${ }^{3}$ Dunav Insurance Company, Belgrade, Serbia \\ Email: zivka.t.przulj@gmail.com
}

Received November 17, 2013; revised December 20, 2013; accepted January 4, 2014

Copyright (C) 2014 Živka Pržulj et al. This is an open access article distributed under the Creative Commons Attribution License, which permits unrestricted use, distribution, and reproduction in any medium, provided the original work is properly cited. In accordance of the Creative Commons Attribution License all Copyrights (C) 2014 are reserved for SCIRP and the owner of the intellectual property Živka Pržulj et al. All Copyright (C) 2014 are guarded by law and by SCIRP as a guardian.

\section{ABSTRACT}

The basic purpose of this research was to determine that, in addition to its demonstrated benefits, the coaching concept is being accepted by a significant number of organizations in Serbia. The possibility of applying the coaching concept, in the given framework, has been investigated by surveying a sample of 133 respondents. The obtained results about management style in Serbian organizations are unexpected, they surpass the subject matter and scope of this research and suggest that significant changes are hapenning in that field that need to be further explored. Research limitations are limited sample and insufficient knowledge of the concept of coaching in Serbia. This article is to explore the possibility of applying the concept of coaching in Serbia. Left to the strict market laws, organizations in Serbia go through inevitable transformation phases in attempting to increase their overall efficiency and performances. Most business enterprises and state institutions are (at least declaratively) willing to embrace changes, but unwilling to accept "Western" models, approaches and methods due to the specific cultural and social conditions and inherited past. This is the first study on this topic in Serbia, which identifies important factors for successful implementation of the concept of coaching and limitations in it.

\section{KEYWORDS}

\section{Coaching; National Culture; Changes; Manager; Organization; Performances}

\section{Introduction}

Nowadays, when we say coaching, it probably concerns one of two things-growing profession worldwide and the growing communication style which is accepted by the leaders in organizations, professors, counselors, parents, and others.

It is evident that the importance and impact of coaching as a concept are growing, first of all thanks to the very visible positive results that have been verified by the individuals who had the opportunity to use this method. One of the most important arguments which justify this claim is the belief that the use of coaching in organizations contributes significantly to increased satisfaction, motivation of employees, their efficiency, and thus creates the preconditions for a climate which supports the full implementation of this approach in the management and promotion of employees in organizations.

Serbia is one of the Eastern-European countries for- med after disintegration of the former Yugoslavia, and one of the last socialist countries that entered the transition process. The transition involves transition from the socialist social system towards civil and democratic and in terms of economy transition towards market economy based on private instead of social (state) ownership. A lot has been expected from these changes in terms of increasing the economic efficiency and accelerating economic development. However, such expectation has not been met mainly due to the unsuccessful privatization of state-owned companies followed by unprecedented unemployment rate, corruption and remains of past business practices expressed by non-market principles.

On the other hand, there is a growing presence of management rights of foreign capital in companies in Serbia, where the change in ownership structure brings about changes in human resource management. Foreign companies often introduce and adapt their management models, which have proved to be efficient in their coun- 
tries and thus bring innovations which are not always in line with the existing cultural patterns. One such innovation is the coaching, which has attained great popularity as a method of development in many developed countries.

Given that all most important systems and concepts in the management of human resources were created in western European culture, it can be assumed that employees in Serbian organizations would have resistance to these approaches. The attempt to implement the system of human resource management which gives good results in the West, can be prevented in these areas because of the impact of different social norms and values. Furthermore, personal identity, being the basis of coaching approach, is more pronounced in developed countries which are concerned with the issues of quality of life rather than in developing countries which are forced to deal with existential problems. The main motive and the importance of research of the possibility of applying the concept of coaching in Serbia derive from that.

\section{Literature and Research Review}

Theoretical basis for this research can be found in the work of several authors dealing in coaching (Laura Whitworth, Karen and Kimsey House [1], Phil Sandahl, Lucy West [2], Mike Milan, Carole Pemberton [3] et other) and culture (first of all Geerd Hofstede and GLOBE study).

Although it has been existing since prehistoric times, Gallwey W. Timothy is considered a pioneer of this new discipline [4]. He wrote several books which have established a new methodology for both personal as well as professional development and excellence in many fields, which he calls the "inner game". Harvard pedagogist and tennis expert, he first introduced a comprehensive teaching method that can be applied in many situations. The essence of his approach lies in the fact that in every human endeavor there are two spheres of engagement: external and internal. The outer game is played on an external arena to overcome obstacles and achieve an external goal. The inner game takes place in the mind of players and obstacles are fear, self-doubt, lapses in perception, constraints and assumptions. The inner game is played to overcome the self-imposed obstacles that prevent an individual or a team to achieve their full potential.

Access to coaching from the aspect of personality skills which affect the performance has its roots in the works of Brounstein. "Coaching is a set of skills to manage the performance of employees in order to achieve results. Being a coach means that you see the manager as a leader: the one who provokes and develops the skills and abilities of employees to achieve the best results" [5]. Starting from this point, coach, leader and manager in the organization are the center of change and actions to achieve the efficiency of the individual and the organization.

Relying on Grant and Kanfer [6], coaching is also considered in this paper as a process: "Coaching is a collaborative, results focused, systematic process in which the coach can increase work performance, life experience, self-directed learning and personal development of the individual who is normal (i.e. non-clinical) population” [7].

Research regarding development of coaching was not conducted in Serbia, nor was the country involved in similar international studies. Frank Bresser et al. in a survey conducted in 2011, found out that there are about 18,000 business coaches in Europe and that it is the continent with the largest number of coaches [8]. However, they are not equally represented-United Kingdom and Germany (almost 20\% of the European population) account for about $70 \%$ of all business coaches on the continent. In contrast, only $5 \%$ of the coaches are in the former communist countries (which comprise about $40 \%$ of the population). Serbia as a country that is not even the EU candidate, has not been included in this study. However, according to the seminars in this field, it can be noted that coaching slowly began to spread in the former Eastern European countries, thanks to international companies, which first "imported" their coaches. Later coaches developed at the local level, through international coaching associations.

In 2011 the research by the Sherpa Institute noted a new trend in leadership development: team coaching and training of managers in coaching skills [9]. Managers and supervisors are increasingly expected to act as coaches. In the programs of coaching skills, the leaders learn how to improve their working relationships and teamwork in order to increase profits. These programs are a relatively new concept.

There is no clear picture of when the coaching began to be used to improve performance and to develop potential senior managers, but it is believed that it has its roots in the second half of the $20^{\text {th }}$ century, of course, at that time-under the auspices of consulting or counseling. Many consultants, trainers and other related professionals claim that they had engaged in coaching before their services were called by that name. Most people agree that under its full name it began to be applied in the late 1980s or early 1990s. This period is generally the time that is related to coaching. In his early years, coaching was often resorted to when it became obvious that managers lack specific skills, for example, not being able to give a good speech on television or in front of large groups. Coach was also often invited because of poor interpersonal relationships between team members or the managers had some personal problems that threatened to endanger their careers, health or family. 
Although coaching and training are highly related concepts, they are not identical. The analysis of the literature leads us to conclude that coaching can increase the value of training. One study shows that coaching included as supporting training, increases the value of training four times [10]. The reason probably lies in the fact that the training is focused on knowledge and skills, and people can have a lot of knowledge and a handful of skills, and despite not being able to use them properly, not being team players, good leaders and not knowing how to inspire each other. To come to a resolution of blocking behavior, individual work with employees is required through coaching.

Coaching as a process of teaching managers evolved from the two related disciplines-consulting and counseling uniting them in its practice [10]. Consulting has a long history that begins in the early twentieth century. At the beginning of the 1990s, clients and consultants were concerned about how to apply their "advice". As a result, the role of consultants has transformed from the advisory role - what the client's organization needs to do-to how to do that. While consulting provides a valuable approach to the content and processes of the client's business, the role of counseling is that managers penetrate deeper and in a more personalized way into created processes, content and results. That led to the creation of an un- breakable bond which makes the nature of coaching. The bond between consulting and counseling is a continuity equally focused on both work and personality.

The title of coach cannot be found in the national nomenclature of occupations, but more and more people have the name of the coach on their business cards. These people can be found in all areas of the economy, the entrepreneurial companies, family businesses, healthcare organizations, government agencies-almost everywhere. Coaching has suffered an identity crisis in its earlier days, and often it was mistaken for life coaching, counseling, consulting and training.

Undoubtedly, coaching is one of the fastest growing phenomenon in the world of business. It is being used as a professional development tool, staff training tool, but also, it becomes more and more embedded in the organizational life in different ways. The results of seven years of data collection in Sherpa Institute prove that the credibility of coaching is growing every year [9]. Coaching has become a permanent part of the organizational development, a well-established management practice in the developed countries of Western Europe and North America.

\section{Implementation of the Concept of Coaching}

While organizations and scientific institutions increasingly recognize the value of coaching and the number of people who work in this discipline significantly increases (either professionally or as a part of their core business) the challenge for organizations is how to successfully implement it and optimize it.

Although coaching is a universal method that can be applied in all societies and cultures, in the Serbian language (and in many other languages) there is no adequate terms that matches the meaning of the word "coaching". In order to provide better insight into the reasons for the introduction of the term in real life, special attention should be paid to the socio-economic framework in which coaching was created, and these are highly developed western European countries. One of the features of these countries is the decentralization of power and decision-making in society.

It usually takes long before a new consciousness has been created and before the majority has accepted new ways and coaching has been incorporated into the corporate consciousness. This includes the dissemination of knowledge and arguments about the effects of coaching on the performance of organizations and individuals, creation of the system of values and culture suitable for the development of coaching.

According to Vikki G. Brock, coaching is becoming the dominant world view and social phenomenon of the 21st century, but it cannot be isolated from the context and the environment [11, pp. 18-20]. It may be noted that the coaching culture is characterized by the following features:

\section{- The pursuit of high performance}

Experience and research has shown that organizations which take advantage of high-performance culture, are the ones in which the teaching is rooted in the DNA of the business. To develop such culture, accept challenges, often means abandon the established practices and rules of conduct, which requires time, commitment and responsibilities of all employees.

\section{- Readiness to change}

Changing behavior and the ways of thinking of the employees in the organization which is faced with the inevitable adjustment to an increasingly demanding market, is the most important challenge for leaders who compete in unpredictable conditions. Coaching allows people to think about themselves and their decisions and guide the customer to find a substitute for the behavior which proved to be wrong.

\section{- Leaders as positive role models}

The organizational culture is created be the leaders at the top. They set the rules of the game: the pace, expectations, what is right and what is wrong-what is acceptable and what is not. Personal development and coaching of employees is put at the top of the priority list and the results in the tables would follow. Great leaders are touching the lives of their followers through coaching. 
The basis of business success is that people have an advantage over tables with figures. When leaders become skilled coaches in practice, they transform their leadership style from being heads to the employees to being coaches to their people. Coaching leaders create powerful, emotionally-intelligent discussions by which the employees change productively and are inspired for action.

\section{- Trust and openness}

Coaching is a form of conversation with the unspoken ground rules in terms of the quality of relationships that must be present: respect, openness, compassion, empathy, and commitment to truth. Coaching is a discovery, awareness and choice. It is a way to effectively empower people to find their own answers, accepting changes. Coaching encourages and supports them in the way of making important decisions. It reflects the change in consciousness: the awareness that there is a choice and clear commitment to choose based on value criteria.

If the culture of coaching is viewed in the context of known cultural research of Hofstede and the GLOBE project, it can be seen that the development of the concept of coaching is suitable in the environment culture with strong individualism and achievement motive, low power distance, low index of uncertainty avoidance, future orientation, high levels of interpersonal trust and balanced ratio of male and female characteristics [12,13]. According to the Hofstede studies, the culture of Serbia has indeed the opposite characteristics [12]. However, organizations can build their own culture and proclaim their own values, which means that, despite the limitations of environment culture, coaching can develop under certain conditions.

\section{Research Methodology}

The aim of this research is to get the answer to the question: is it possible to use coaching as a method that has come from the West, to increase the efficiency and performance of employees and the organization as a whole in Serbia as a specific social/cultural area.

Based on the defined object and purpose of the research, as well as the aforementioned assumptions and information available, the basic hypothesis is formulated as follows:

Despite the proven benefits of the concept of coaching and its popularity in the world, organizations in Serbia are still not ready to widely accept the concept.

In the process of proving this basic hypothesis, we started from the following additional assumptions:

- Acceptance of the concept of coaching is influenced by the knowledge of managers about this concept and its usefulness.

- Organisation in Serbia with an autocratic style of leadership are not ready to accept the concept of coaching.

- Acceptance of the concept of coaching depends on the willingness of managers to make changes in the organization they manage.

- The culture which is characterized by uncertainty avoidance and power distance (being the characteristics of the culture of Serbia) is resistant to accepting the concept of coaching.

The research is of an exploratory type, and has been implemented on the territory of Serbia in profit and nonprofit organizations. The basic set of respondents are employees who perform executive and managerial jobs. The sample is random, and includes 133 survey respondents, which is a modest number compared to the questionnaire sent by e-mail. In addition to the questionnaire, the respondents were given a cover letter that contained information related to the subject, object and purpose of the research.

The study included $62.4 \%$ women and $37.6 \%$ men. According to the educational structure, the research included 57.9 employees with university degree, 18\% of master's degree holders and $\mathrm{PhD}$ holders, $16.5 \%$ of high school graduates and $7.5 \%$ with secondary school diploma.

The research included all ages - from 24 to 60 years of age, but the highest percentage (51.4\%) entailed the most productive age of life-from 35 to 45 years of age.

For the purpose of this research a questionnaire was composed comprising the claims related to the issue of representation of coaching in Serbia in addition to questions to gather demographic information about respondents and data about the company. Compliance with offered attitudes was evaluated on the Likert scale.

The answers were analyzed in SPSS v 19 software package, and for the analysis and interpretation the following were used: descriptive statistics, contingency coefficient, analysis of variance, Pearson correlation coefficient and factor analysis.

Preparation and research commenced in early February 2012 and was completed in January 2012.

Sticking to the division of the company as defined by the European Union, the study included 27.8\% small, $22.6 \%$ medium and $49.6 \%$ large companies and organizations.

Statistical analysis of the data obtained in this study did not give significant coefficients of contingency characteristics of the respondents (gender, age, level of education) and the acceptance of the concept of coaching, which refers to the characteristics of the organizations involved in this research (ownership, size).

\section{Review and Discussion of the Research Results}

To determine how the questions and indicators used in the questionnaire are relevant to the study of repre- 
sentation and possibilities of developing coaching in Serbia, the correlation analysis and contingency coefficient were used, by which hypotheses are tested.

It was confirmed that the acceptance of the concept of coaching explored through three indicators (implementation of coaching in the organization, the existence of internal coaches and basic training of managers for coaching) depends on the knowledge of managers about the concept and its usefulness. Statistically significant correlation was obtained at the level 0.01 between acceptance and familiarity of managers with the concept of coaching, i.e. it was found out that the more managers become familiar with the concept of coaching, the more coaching would be implemented, thus increasing the number of internal coaches and the number of managers trained in the basics of coaching.

These results (Table 1) confirm that the presentation of coaching and its benefits are the key to acceptance of the concept. The acceptance of the concept of coaching (if observed as a synergy of three variables- the implementation of coaching in the organization, the existence of internal coaches and basic training of managers for coaching) first of all depends on the knowledge of managers about the concept and its usefulness.

However, the hypothesis that organizations in Serbia which have an autocratic management style are not ready to accept the concept of coaching, was only partly confirmed. Of the three variables that are defined to constitute acceptance of the concept of coaching (implementation of coaching in the organization, the existence of internal coaches and basic training of managers for coaching) only two of them show a relationship that is statistically significant, which can be seen in the tables following.

Table 2 shows that there is a correlation between leadership style and implementation of coaching and that the contingency coefficient between these two variables shows statistical significance at the level 0.01 (Table 3) and tells us that coaching is mostly implemented in the organizations that foster democratic/participative management style.

The same can be said for a correlation between leadership style and the existence of internal coaches in the organization (Tables 4 and 5), i.e. in organizations that foster democratic/participative management style there is a significantly higher number of internal coaches. Only the correlation was not found between leadership style and basic training of managers in coaching (Tables 6 and 7).

Table 8 confirms that there is a correlation among the willingness to manage change by managers and all three variables of acceptance of the concept of coaching. All three correlations are significant, suggesting that in organizations where managers are ready to manager change the concept of coaching will be better accepted.

In Table 9 the correlation, which is not high though significant, between not accepting the novelties and charishing power distance on the one hand and the acceptance of the concept of coaching on the other. This confirms the assumption that in the organizations which foster power distance novelties are not easily accepted (high uncertainty avoidance), and the concept of coaching is more difficult to accept. This confirms the hypothesis that culture which is characterized by uncertainty avoidance and power distance (being the characteristics of Serbian culture) is resistant to accepting the concept of coaching.

In order to obtain a more complete results, in the analysis of data collected in the study factor analysis was applied which would allow us to to determine whether there are factors and which of these are key to the acceptance of the concept of coaching in Serbian organizations.

The factor analysis included variables that meet Kaiser-Meyer-Olkin coefficient of measure of eligibility of the correlation matrix for factorization and the Bartlett's test of significance and they amount to 0.88 . By factor analysis on the basis of the commong characteristics that are dominant, three factors were isolated which explain $69.16 \%$ of variance. These factors were named as follows:

1) Climate for coaching-The first factor entails the following variables: familiarity of managers with the concept of coaching, implementation of coahing, the existence of internal coaches, training of managers, stage of coaching development, nurturing coaching culture and coaching experience (Table 10).

2) Openness of the organization-The second factor includes variables such as: readiness for management of change, innovation acceptance and not nurturing power distance.

3) Openness of the individual-The third factor entails coaching as a concept of learning and education.

The decision on the number of factors was made based on Guttman-Keiser approach. The components were rotated by varimax method.

Figure 1 clearly shows that the coaching climate is the first and most important factor that affects the possibility of application of coaching in the organization. This climate, as well as all other organizational climates, is filtered from top to bottom. Therefore, leaders have a key role in its formation. Leaders can choose any style of management, but if they are familiar with the coaching style (situational, emotional and competence-based leadership), are likely to recognize the benefits of applying the concept of coaching.

The openness of the organization is another factor which is the necessary precondition for the establishment 
Table 1. Acceptance of the concept of coaching and familiarity with the concept by the managers.

\begin{tabular}{|c|c|c|c|c|c|}
\hline \multicolumn{6}{|c|}{ Correlations } \\
\hline & & $\begin{array}{l}\text { Familiarity of managers with } \\
\text { the concept of coaching }\end{array}$ & $\begin{array}{l}\text { Implementation of } \\
\text { coaching }\end{array}$ & Internal coaches & $\begin{array}{c}\text { Training of } \\
\text { managers }\end{array}$ \\
\hline \multirow{3}{*}{$\begin{array}{l}\text { Familiarity of managers with } \\
\text { the concept of coaching }\end{array}$} & Pearson Correlation & 1 & $0.704^{* *}$ & $0.445^{* *}$ & $0.575^{* *}$ \\
\hline & Sig. (2-tailed) & & 0.000 & 0.000 & 0.000 \\
\hline & $\mathrm{N}$ & 133 & 133 & 133 & 133 \\
\hline \multirow{3}{*}{ Implementation of coaching } & Pearson Correlation & $0.704^{* *}$ & 1 & $0.490^{* *}$ & $0.686^{* *}$ \\
\hline & Sig. (2-tailed) & 0.000 & & 0.000 & 0.000 \\
\hline & $\mathrm{N}$ & 133 & 133 & 133 & 133 \\
\hline \multirow{3}{*}{ Internal coaches } & Pearson Correlation & $0.445^{* *}$ & $0.490^{* *}$ & 1 & $0.561^{* *}$ \\
\hline & Sig. (2-tailed) & 0.000 & 0.000 & & 0.000 \\
\hline & $\mathrm{N}$ & 133 & 133 & 133 & 133 \\
\hline \multirow{3}{*}{ Training of managers } & Pearson Correlation & $0.575^{* *}$ & $0.686^{* *}$ & $0.561^{* *}$ & 1 \\
\hline & Sig. (2-tailed) & 0.000 & 0.000 & 0.000 & \\
\hline & $\mathrm{N}$ & 133 & 133 & 133 & 133 \\
\hline
\end{tabular}

Table 2. Management style/Implementation of coaching.

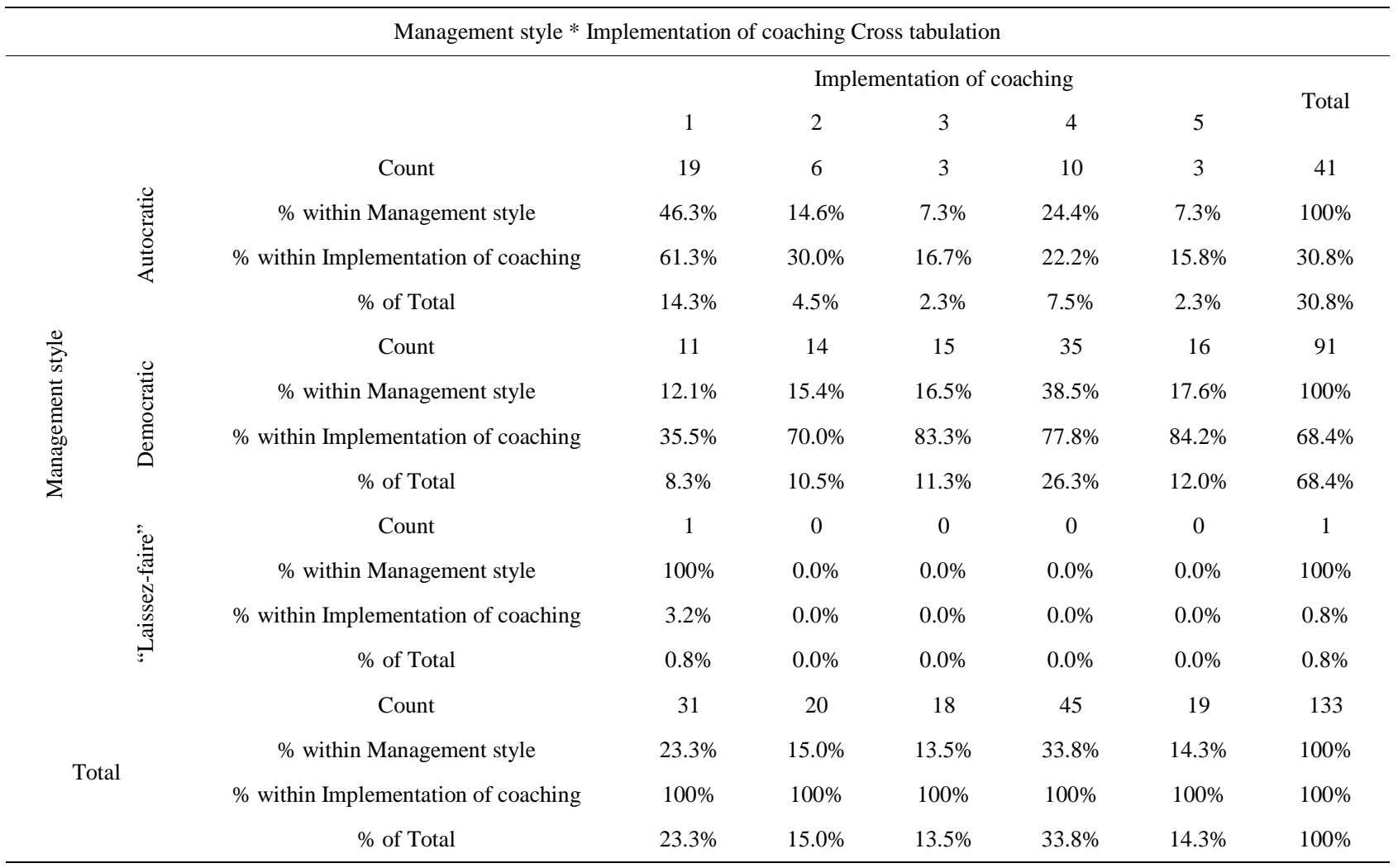

Table 3. Contingency coefficient leadership style and implementation of coaching.

\begin{tabular}{|c|c|c|c|}
\hline \multicolumn{4}{|c|}{ Symmetric Measures } \\
\hline \multirow{3}{*}{ Nominal by Nominal } & & Value & Approx. Sig. \\
\hline & Contingency Coefficient & 0.384 & 0.003 \\
\hline & & 133 & \\
\hline
\end{tabular}


Table 4. Management style and internal coaches.

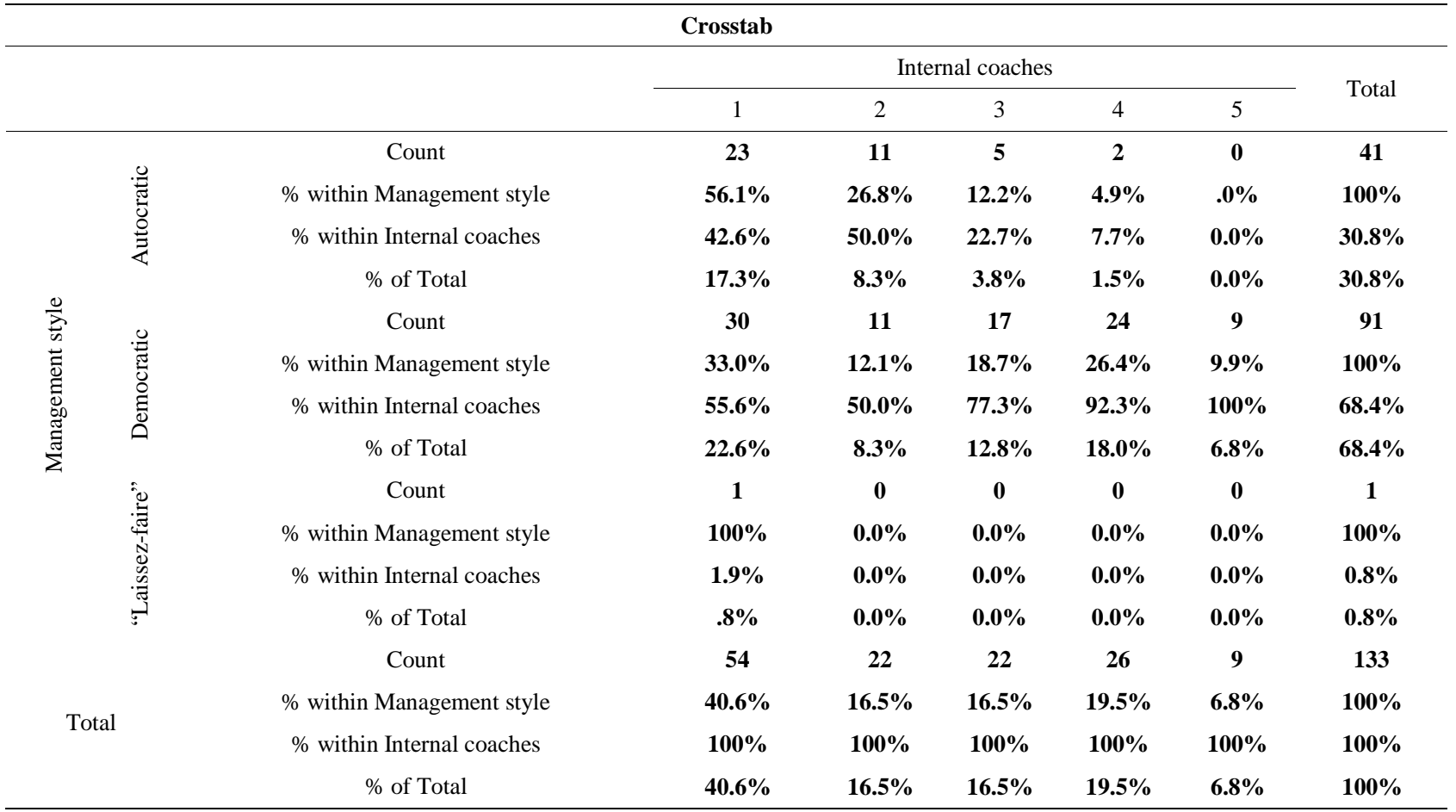

Table 5. Correlation between leadership style and the existence of internal coaches.

\begin{tabular}{llcc}
\hline & Symmetric Measures & & \\
\hline & & & Value \\
Nominal by Nominal & & Contingency Coefficient & $\mathbf{0 . 3 6 5}$ \\
& N of Valid Cases & $\mathbf{0 . 0 0 9}$ & $\mathbf{1 3 3}$ \\
\hline
\end{tabular}

Table 6. Leadership style and basic training of managers in coaching.

\begin{tabular}{|c|c|c|c|c|c|c|c|c|}
\hline \multicolumn{9}{|c|}{ Crosstab } \\
\hline & & & \multicolumn{5}{|c|}{ Training of managers } & \multirow{2}{*}{ Total } \\
\hline & & & 1 & 2 & 3 & 4 & 5 & \\
\hline \multirow{10}{*}{ 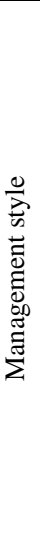 } & \multirow{3}{*}{ 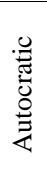 } & Count & 17 & 9 & 6 & 7 & 2 & 41 \\
\hline & & \% within Management style & $41.5 \%$ & $22.0 \%$ & $14.6 \%$ & $17.1 \%$ & $4.9 \%$ & $100 \%$ \\
\hline & & $\%$ within Training of managers & $45.9 \%$ & $39.1 \%$ & $25.0 \%$ & $18.9 \%$ & $16.7 \%$ & $30.8 \%$ \\
\hline & \multirow{4}{*}{ 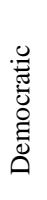 } & Count & 19 & 14 & 18 & 30 & 10 & 91 \\
\hline & & \% within Management style & $20.9 \%$ & $15.4 \%$ & $19.8 \%$ & $33.0 \%$ & $11.0 \%$ & $100 \%$ \\
\hline & & $\%$ within Training of managers & $51.4 \%$ & $60.9 \%$ & $75.0 \%$ & $81.1 \%$ & $83.3 \%$ & $68.4 \%$ \\
\hline & & $\%$ of Total & $14.3 \%$ & $10.5 \%$ & $13.5 \%$ & $22.6 \%$ & $7.5 \%$ & $68.4 \%$ \\
\hline & \multirow{3}{*}{ 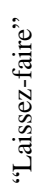 } & Count & 1 & $\mathbf{0}$ & $\mathbf{0}$ & $\mathbf{0}$ & 0 & 1 \\
\hline & & $\%$ within Training of managers & $2.7 \%$ & $0.0 \%$ & $0.0 \%$ & $0.0 \%$ & $0.0 \%$ & $0.8 \%$ \\
\hline & & $\%$ of Total & $.8 \%$ & $0.0 \%$ & $0.0 \%$ & $0.0 \%$ & $0.0 \%$ & $0.8 \%$ \\
\hline \multirow{4}{*}{\multicolumn{2}{|c|}{ Total }} & Count & 37 & 23 & 24 & 37 & 12 & 133 \\
\hline & & \% within Management style & $27.8 \%$ & $17.3 \%$ & $18.0 \%$ & $27.8 \%$ & $9.0 \%$ & $100 \%$ \\
\hline & & $\%$ within Training of managers & $100 \%$ & $100 \%$ & $100 \%$ & $100 \%$ & $100 \%$ & $100 \%$ \\
\hline & & $\%$ of Total & $27.8 \%$ & $17.3 \%$ & $18.0 \%$ & $27.8 \%$ & $9.0 \%$ & $100 \%$ \\
\hline
\end{tabular}


Table 7. Contingency coefficient between leadership style and basic training of managers in coaching.

\begin{tabular}{|c|c|c|c|}
\hline \multicolumn{4}{|c|}{ Symmetric Measures } \\
\hline & & Value & Approx. Sig. \\
\hline \multirow[t]{2}{*}{ Nominal by Nominal } & Contingency Coefficient & 0.285 & 0.162 \\
\hline & & 133 & \\
\hline
\end{tabular}

Table 8. Correlation between the readiness of managers to manage change and the acceptance of the concept of coaching.

\begin{tabular}{|c|c|c|c|c|c|}
\hline \multicolumn{6}{|c|}{ Correlations } \\
\hline \multirow{4}{*}{$\begin{array}{l}\text { Readiness to } \\
\text { change }\end{array}$} & & Readiness to change & Implementation of coaching & Internal coaches & Training of managers \\
\hline & Pearson Correlation & 1 & $0.488^{* *}$ & $0.261^{* *}$ & $0.355^{* *}$ \\
\hline & Sig. (2-tailed) & & 0.000 & 0.002 & 0.000 \\
\hline & $\mathrm{N}$ & 133 & 133 & 133 & 133 \\
\hline
\end{tabular}

${ }^{* *}$ Correlation is significant at the 0.01 level (2-tailed). This confirms the assumption that the concept of coaching would be better implemented in organizations in which managers are willing to accept and manage change.

Table 9. Correlation between accepting novelty by the managers and the concept of coaching.

\begin{tabular}{|c|c|c|c|c|c|c|}
\hline \multicolumn{7}{|c|}{ Correlations } \\
\hline & & $\begin{array}{c}\text { Non acceptance of } \\
\text { novelties }\end{array}$ & Power distance & $\begin{array}{l}\text { Implementation of } \\
\text { coaching }\end{array}$ & Internal coaches & $\begin{array}{c}\text { Training of } \\
\text { managers }\end{array}$ \\
\hline \multirow{3}{*}{$\begin{array}{l}\text { Non acceptance } \\
\text { of novelties }\end{array}$} & Pearson Correlation & 1 & $0.539^{* *}$ & $-0.359^{* *}$ & $-0.241^{* *}$ & $-0.323^{* *}$ \\
\hline & Sig. (2-tailed) & & 0.000 & 0.000 & 0.005 & 0.000 \\
\hline & $\mathrm{N}$ & 133 & 133 & 133 & 133 & 133 \\
\hline \multirow{3}{*}{ Power distance } & Pearson Correlation & $0.539^{* *}$ & 1 & $-0.272^{* *}$ & $-0.280^{* *}$ & $-0.231^{* *}$ \\
\hline & Sig. (2-tailed) & 0.000 & & 0.002 & 0.001 & 0.007 \\
\hline & $\mathrm{N}$ & 133 & 133 & 133 & 133 & 133 \\
\hline
\end{tabular}

${ }^{* *}$ Correlation is significant at the 0.01 level (2-tailed).

Table 10. Rotated component matrix.

Rotated Component Matrix

\begin{tabular}{|c|c|c|c|}
\hline \multicolumn{4}{|c|}{ Rotated Component Matrix ${ }^{\mathrm{a}}$} \\
\hline & \multicolumn{3}{|c|}{ Component } \\
\hline & 1 & 2 & 3 \\
\hline Readiness for change & 0.379 & 0.668 & 0.012 \\
\hline Non-acceptance of novelty & -0.214 & -0.743 & -0.235 \\
\hline Familiarity of managers with the concept of coaching & 0.753 & 0.337 & -0.008 \\
\hline Implementation of coaching & 0.839 & 0.216 & 0.096 \\
\hline Internal coaches & 0.713 & 0.107 & -0.046 \\
\hline Training of managers & 0.834 & 0.096 & 0.020 \\
\hline Coaching stage & 0.800 & 0.181 & 0.128 \\
\hline Existence of coaching culture & 0.707 & 0.518 & 0.083 \\
\hline Coaching as a concept of learning & 0.222 & 0.086 & 0.727 \\
\hline Experience with coaching & 0.876 & 0.345 & 0.199 \\
\hline Education & -0.090 & 0.021 & 0.797 \\
\hline
\end{tabular}

Extraction Method: Principal Component Analysis. Rotation Method: Varimax with Kaiser Normalization. ${ }^{\mathrm{a}}$ Rotation converged in 4 iterations. 


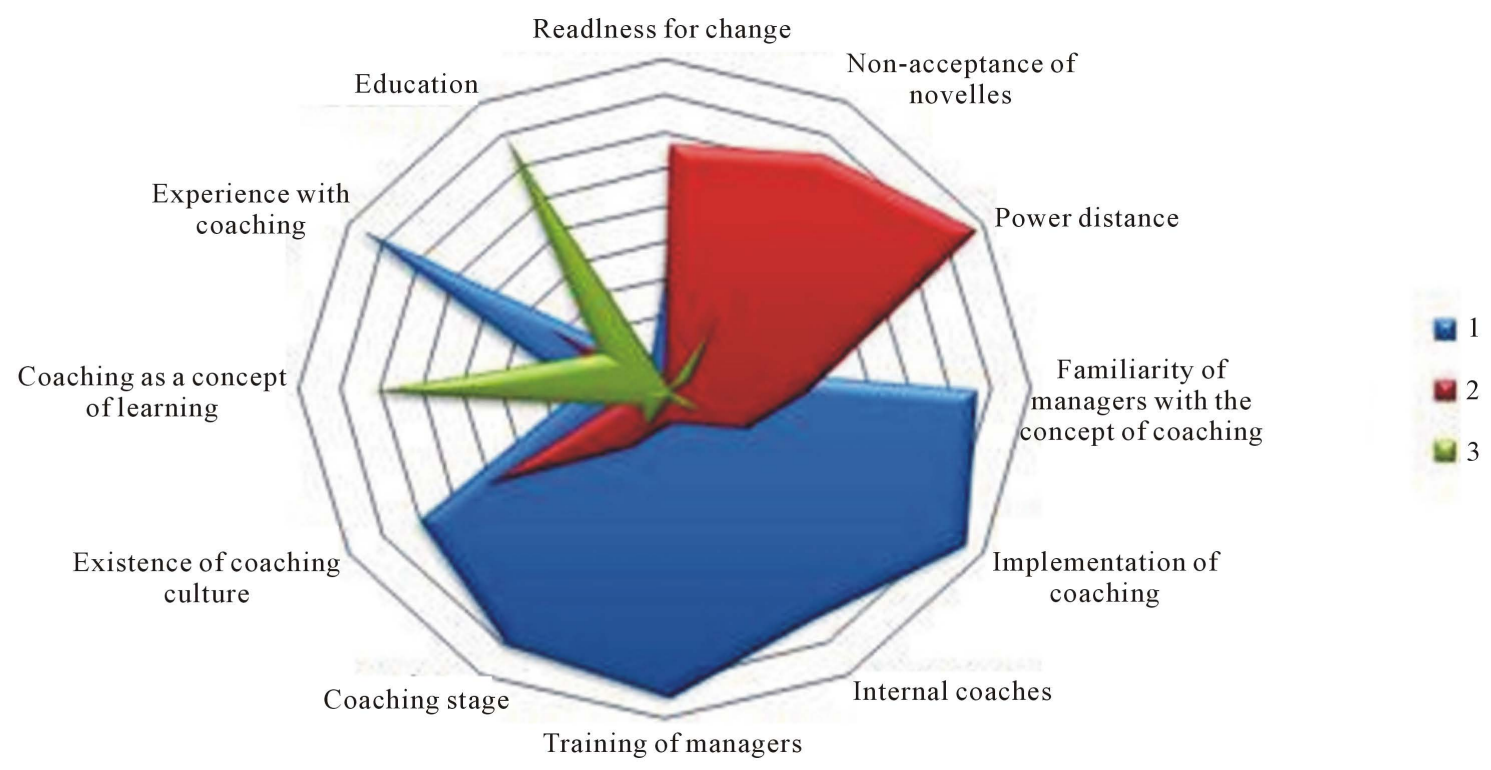

Figure 1. The most important factors.

of coaching climate, and the possibility of development of coaching in the organization. If managers do not foster power distance, if they accept novelties and are ready to manage change, they will accept the concept of coaching because it enables positive impact on the organization.

The third factor is the openness of the individual and it represents a synthesis of two variables - the acceptance of coaching as a concept of learning that affects selfevelopment and formal education of an individual. Although formal education is not the only true indicator of education of an individual, in this research we have found out that coaching would easier accepted by people who have levels of education higher than the secondary school. This tells us that if we want coaching to be fully accepted in the organization (not only from top to bottom), the very concept and its usefulness for the individual has to be better presented to the employees with a secondary school diploma.

\section{Concluding Remarks}

The research results have confirmed that despite the proven benefits of the concept of coaching and its popularity in the world, organizations in Serbia are still not ready to widely accept this concept. All remarks mentioned above point to the need to intensify the efforts and preparation of the organizations for the introduction of coaching in those organizations in which it has not been introduced as well as its systematized usage in human resource management in Serbia.

This research supports the hypothesis that organizations more easily decide to implement the concept of coaching if they have more information about the possibility of coaching in achieving high individual and or- ganizational performance. This suggests the need of expanding knowledge about this concept, which is one of the key preconditions for this concept to be accepted.

Relying on the results of the existing relevant research in the field of culture and leadership styles that are most used in Serbia and the obtained correlation between the autocratic style and coaching, it can be said that one of the major obstacles to the development of coaching in this country is the existence of high power distance, which conditions largely autocratic management style. The high degree of authoritarianism and power distance itself preclude the application of the concept of coaching, which is based on completely different principlesrespect, dialogue, feedback and self-actualization.

Coaching as a method of individual and organizational development is basically aimed at supporting and encouraging change. Not surprisingly though, the correlation between the willingness to change and application of coaching has been confirmed. However, one characteristic of Serbian culture is the high level of uncertainty avoidance, which is not suitable for the development of this concept. This has confirmed assumptions about the negative impact of cultural factors on the dynamic development of this concept in Serbia.

However, despite significant contributions, this study has certain limitations. The basic limitations stem from the research objective, as well as the number and structure of the respondents and their understanding of the questions in the questionnaire. It should be noted that respondents' attitudes depend on their knowledge of the essence and benefits of this concept in the country where it has not been developed yet. The value of the results should be viewed from the perspective of providing 
quality information to the scientific and professional community, which may contribute to the further development of measuring the contribution of coaching to the success of organization and better management of individual and organizational development.

\section{REFERENCES}

[1] K. Kimsey-House, et al., "Co-Active Coaching: Changing Business, Transforming Lives,” Nicholas Brealey Publishing, London, 2007.

[2] L. West and F. Staub, "Content Focused Coaching Transforming Mathematics Lessons,” Heinemann, Portsmouth, 2003.

[3] C. Pemberton, "Coaching to Solutions," Reutlege, New York, 2006.

[4] W. T. Gallwey, “The Inner Game of Tennis,” Random House, New York, 1974.

[5] M. Brounstein, "Coaching and Mentoring for Dummies,"
Davies Black Publishing, Palo Alto, 2005, p. 14.

[6] F. H. Kanfer and A. P. Goldstein, "Helping People Change; a Textbook of Methods,” Pergamon Press, New York, 1975.

[7] A. M. Grant, "Solution-focused Coaching: Managing People in a Complex World,” Momentum, London, 2003, p. 87.

[8] The Global Coaching Survey, 2008/09. http://libraryofprofessionalcoaching.com/wp-app/wp-cont ent/uploads/2013/02/LPC_0117.pdf

[9] Sherpa Executive Coaching Survey, Seventh Annual.

[10] L. West and M. Milan, “The Reflecting Glass,” Palgrave, Basingstoke, 2001, pp. 3,29.

[11] V. G. Brock, "The Secret History of Coaching," EMCC, Dublin, 2010.

[12] G. Hofstede, “Culture’s Consequences,” Sage Publications, 1984.

[13] R. House, et al., "The GLOBE Study of 62 Societies," Sage Publications, 2004. 